\title{
Viajar é preciso: Theodor Koch-Grünberg e a Völkerkunde alemã do século XIX
}

\author{
Erwin H. Frank \\ Professor do Departamento de Antropologia - UFRR
}

RESUMO: Tomando a etnografia de Theodor Koch-Grünberg como realização ideal do projeto científico da Völkerkunde (antropologia) alemã desde a sua invenção por Waitz e, principalmente, Adolf Bastian, até a sua autoeliminação nos primórdios do Terceiro Reich, analisamos inicialmente as raízes desse projeto na filosofia alemã, desde Herder até a ruptura neokantiana entre as ciências naturais e sociais (ou culturais) na metade do século XIX. Em seguida mostramos que, transformados em programa etnográfico, os pressupostos epistêmicos da Völkerkunde eram, desde o início, condenados ao fracasso, não obstante os heróicos esforços como este de Koch-Grünberg.

PALAVRAS-CHAVE: história da antropologia, Völkerkunde, Theodor Koch-Grünberg, etnografia.

"[...] etnografia é antropologia, ou não é nada." (Sahlins, 2004, p. 17) 


\section{Introdução}

Em 1898, o conhecido etnógrafo e explorador alemão Hermann Meyer convidou um jovem filólogo de nome Theodor Koch, recém-formado "instrutor" de latim e de grego clássico em um Gymnasium provinciano da Alta Hessen, para cuidar da parte lingüística de sua segunda expedição ao Brasil ${ }^{1}$. Cerca de dois anos depois, uma publicação etnográfica de Koch chamou a atenção do fundador e diretor do Königliches Museum für Völkerkunde (Real Museu de Etnologia) Adolf Bastian, representante principal do reduzido círculo de aficionado da Völkerkunde (etnologia) na época, que convidou o autor (o qual prontamente adicionara o nome de sua cidade natal, Grünberg, ao nome de família) para "estagiar" no Museu Etnográfico de Berlim - oferta algo indecente, pois os estágios no museu são voluntários, isto é, não remunerados. Mesmo assim, Koch-Grünberg aceitou a oferta e até $1909^{3}$ trabalhou na seção latino-americana do museu, orientado, entre outros, por Karl von den Steinen (aliás, tio de Hermann Meyer) e por Eduard Seler, ou seja, pela nata dos americanistas da época (Kutscher, 1976).

Um ano após a sua chegada a Berlim, Theodor Koch-Grünberg apresentou a tese de doutoramento (aliás, ainda mais filológica do que etnográfica) à Faculdade de Filosofia da Universidade de Würzburg. Imediatamente depois (1903), iniciou a sua segunda expedição ao Brasil, ao longo da qual percorreu os cursos dos principais afluentes do rio Negro e do Japurá, colecionando uma infinidade de valiosíssimos dados etnográficos, geográficos e lingüísticos, além de uma farta quantidade de artefatos indígenas ${ }^{4}$. De volta à Alemanha (em 1905), o agora ajudante científico do museu resumiu os resultados de sua façanha em uma obra de dois volumes, cuja publicação lhe deu imediatamente uma sólida reputação internacional como etnógrafo 5 . 
Em 1909, a Universidade de Freiburg, no extremo sudoeste da Alemanha, outorga a livre-docência a Koch-Grünberg ${ }^{6}$, abrindo-lhe finalmente também as portas da academia alemã, isto é, das universidades, mesmo que meramente na posição algo marginal de Privatdozent - sem vaga no quadro universitário ${ }^{7}$. Talvez a causa disso tenha sido porque, pouco mais de um ano depois de começar a ensinar Völkerkunde em Freiburg, Koch-Grünberg tenha partido uma vez mais rumo à Amazônia, onde nos dois anos seguintes (1911-1912) subiu o rio Branco, escalou o monte Roraima, seguiu pelo rio Urariquera além da altura da serra Parima, desceu o rio Ventuari (na Venezuela) até a sua confluência com o Orenoco, retornando a Manaus via canal Caciquiare (cf. KochGrünberg, 1916-1928 - particularmente, Band I, 1917).

De volta a Freiburg, em 1913, já esperava por ele uma outra promoção, desta vez o título de professor extraordinário, o qual garante finalmente estabilidade acadêmica, posição esta que, mesmo assim, ocupa por menos de dois anos, pois em 1915 ele é chamado para administrar cientificamente o Museu Linden, em Stuttgart. Com a direção do museu em Stuttgart, Koch-Grünberg está finalmente no ápice de sua carreira, fazendo parte do seleto grupo dos "mandarins" isto é, do reduzido círculo daqueles que, via cartas de recomendação (dadas ou negadas), referências e recensóes (positivas ou negativas), fizeram e desfizeram carreiras antropológicas na Alemanha daquela época.

Mas também nessa posição Koch-Grünberg ficou somente por pouco tempo, pois no início dos anos 1920 uma grave crise político-institucional, mas sobretudo econômico-financeira, abalou a Alemanha em conseqüência de sua derrota na Primeira Guerra Mundial, atingindo até a sua brilhante carreira. Em 1923, o Museu Linden é obrigado a fechar as portas por "total falta de recursos", momento em que seu diretor científico antecipa a despedida, renunciando a seu cargo. Nos meses seguintes há intensas negociações nos bastidores da Deutsche Gesellschaft für 
Völkerkunde (Sociedade Alemã de Antropologia) com a finalidade de levá-lo de volta a Berlim, desta vez como professor extraordinário da Universidade Humboldt. Mesmo assim, em meio a essa movimentação de seus colegas a seu favor, Koch-Grünberg decide aceitar um convite de Hamilton Rice, conhecido geógrafo e aventureiro nova-iorquino, para participar de outra expedição (organizada e chefiada por este último) com a finalidade declarada de buscar as fontes do Orenoco (Rice, 1928 e 1978).

Em 1924, Koch-Grünberg estava, pois, pela quarta e última vez na Amazônia. Mas, esperando a chegada do resto da expedição no pequeno povoado de Vista Alegre, perto da atual Caracaraí (RR), ele sofre um ataque virulento, provavelmente de malária, que provoca a sua morte no dia 8 de outubro de 1924 (cf. Hartmann, 1980; Zerries, 1972; Faber, 1956; Turza, 1980).

\section{Um etnógrafo nato?}

A breve revisão da carreira de Theodor Koch-Grünberg não deixa margem à dúvida: aquilo que a dinamizou, que inicialmente abriu para um desconhecido filólogo o conhecimento de uma ciência que nunca havia estudado, proporcionando-lhe depois, em rápida seqüência, sempre novas e as mais elevadas honrarias, títulos e cargos, tanto no âmbito museológico como no campo acadêmico - ainda pouco diferenciados naquela época (Voell, 2001) - não foram contribuições teórico-paradigmáticas de destaque (na realidade, raras nesse autor ${ }^{9}$ ), mas o reconhecimento pleno, por parte dos chefôes da Völkerkunde, de seu excepcional talento como etnógrafo, ou seja, a sua rara capacidade de imaginar, organizar e levar a cabo viagens de pesquisa (de ordenar uma coleção etnográfica) e de resumir os resultados dessas viagens em textos (monografias 
e/ou ensaios) que, aos olhos desses chefōes, contribuíam idealmente para o próprio projeto científico ${ }^{10}$.

Mas, afinal, que projeto foi esse? E como se explica que, mesmo antes de sua primeira viagem ao Brasil, esse jovem provinciano formado em filologia já soubesse o que demandava tal projeto? Começaremos com a última pergunta.

\section{Um Bildungsbürger na Amazônia}

Theodor Koch nasceu em 1872, em Grünberg, uma pequena cidade a nordeste de Frankfurt (Main). Filho de pastor luterano, cresceu no ambiente típico de uma classe culturalmente hegemônica na Alemanha da época, embora politicamente ainda marginalizada num Reich só recentemente (1871) unificado pelos Junkers prussianos. Autodenominava-se aquela classe de Bildungsbürgertum - burguesia de educação ou de formação (cf. Giesen, 1993, p. 105-15; Giesen \& Junge 1991; Kocka, 1987; Habermas, 1962) - que era composta principalmente de profissionais autônomos, do baixo clero (sobretudo da igreja luterana) e de servidores públicos (Beamte) - entre estes últimos, sobretudo professores de todos os escalóes (da escola primária aos professores universitários) - assim como de uma quantidade significativa dos próprios Junkers empobrecidos.

A característica principal da classe foi, é claro, a sua Bildung, conceito que no alemão da época significava muito além de "educação formal". $\mathrm{Na}$ realidade, o Bildungsideal visou em relação a ela e de maneira central o aperfeiçoamento sistemático (consciente e constante) da Seele (alma, espírito) de cada um de seus integrantes, via o trabalho dedicado, o estrito autocontrole (disciplina, austeridade) e os estudos continuados (leitura) nos campos tanto das ciências (principalmente filosofia e história) 
Erwin H. Frank. Viajar é preciso...

como da poesia - ideal considerado plenamente pelos grandes filósofos-poetas alemães do século XVIII (de Lessing a Goethe). Filosoficamente idealista, politicamente liberal e humanista no que dizia respeito ao ético-moral, os Bildungsbürger entenderam-se como elite não em contraste com o "povão", mas em função dele.

Foi em obediência aos mandos do Bildungsideal dessa classe que o jovem Theodor Koch se formou em filologia, mesmo que desde aquela época tenha cultivado uma paixão secreta que marcaria a sua vida e a sua carreira, pois como tantos outros membros do Bildungsbürgertum também seu pai era assinante do Globus, talvez junto com Petermann's Mitteilungen, o mais popular de uma série de periódicos semicientíficos da época especializados em relatos de viagens. Foi por meio de Globus que o jovem Theodor acompanhou as aventuras dos grandes viajantes científicos de então (alemães e outros) na Ásia, na África e na América Latina. Também por intermédio desse veículo, o recém-licenciado professor de latim e grego soube que Hermann Meyer procurava um especialista em vergleichende Sprachenkunde (lingüística comparativa) para a sua segunda expedição alemã ao Alto Xingu - região descoberta 15 anos antes (1884) por Karl von den Steinen (Schaden, 1993).

Mas a importância do Globus para a carreira de Koch-Grünberg não pára aí. Não cabe qualquer dúvida quanto ao fato de que foi também por meio dessas leituras que, mesmo antes de sua viajem com Meyer, Koch-Grünberg estava já profundamente familiarizado com a finalidade e a metodologia de uma nova ciência que, desde os anos 1850, havia ganhado contornos, principalmente nos trabalhos do ex-médico Adolf Bastian e nos do geógrafo Theodor Waitz (1858), num permanente e intenso diálogo crítico (com freqüência, desenvolvido nas próprias páginas do Globus) com os defensores de diversos projetos alternativos, como a Psychologie (Psicologia) de Herbart e Fechner (Köpping, 1983, p. 88), a Völkerpsychologie de Lazarus e Steintal (1859), ou também as 
geografias culturais e/ou humanas de Ritter (1852) e Ratzel (1891). Todos esses projetos tinham em comum a tentativa de seus criadores de finalmente resolverem cientificamente a questão (em última instância romântica ou herderiana, segundo o caso) da causa ou razão de ser das diferenças e das semelhanças entre povos distantes no tempo e/ou no espaço, sendo uma das principais dessas diferenças entre os seus criadores e defensores o grau de influência neokantiana versus o positivismo (de Mach) sobre as suas propostas metodológicas.

\section{Raízes de um projeto}

Faz dez anos agora que Matti Bunzl mostrou de forma convincente que a idéia-chave da Völkerkunde foi traçada já idealmente (nem sequer pela primeira vez) nos últimos anos do século XVIII, num esboço pouco conhecido de Wilhelm von Humboldt, chamado Plan einer vergleichenden Antropologie (Esboço de uma Antropologia Comparativa; cf. Bunzel, 1996). Nesse trabalho, Humboldt argumenta que o Gattungscharakter da humanidade, isto é, o caráter da humanidade como espécie realiza-se historicamente em uma variedade quase ilimitada de Nationalcharaktere (plural de caráter nacional) ou Volkscharaktere (caracteres de povos) que, por sua vez, se refletem diretamente nos costumes, nas crenças, na língua e nas artes de cada povo e época ${ }^{11}$.

Para o estudo do Gattungscharakter por meio dos Volkscharaktere, Humboldt recomenda então uma síntese das epistemologias de Herder e Kant, isto é, do espírito (empirista) das ciências naturais (iluministas) e da hermenêutica, aliás, marcadamente antiiluminista de Herder (Bunzl, 1996, p. 22). Mais concretamente, Von Humboldt propõe que se estudem os condicionamentos metafísicos do espírito humano (o Gattungscharakter, uma idéia profundamente kantiana em roupagem 
Erwin H. Frank. Viajar é preciso...

terminológica herderiana) por meio da observação empírica, embora holistica e não reducionista, de seus efeitos sobre os diversos Volkscharaktere em contextos histórico-ambientais distintos.

Desafortunadamente, após a formulação inicial, Wilhelm von Humboldt nunca mais voltou ao esboço juvenil grandioso, se deixarmos de levar em conta as suas famosas pesquisas no campo da lingüística comparativa que, sem dúvida, constituem contribuições tematicamente específicas ao projeto geral da Vergleichende Anthropologie. Citamos esse trabalho aqui somente como uma concretização algo precoce de um ideário amplamente compartilhado pelos Bildungsbürger alemães ao longo de todo o século XIX - entre outros, pelo mais famoso deles em sua época, o irmão de Wilhelm von Humboldt, Alexander ${ }^{12}$.

De fato, considerando que o esboço de Wilhelm foi publicado pela primeira vez somente no final daquele século, fica claro que foi principalmente por meio das publicaçóes de Alexander que as idéias de Wilhelm von Humboldt chegaram a influenciar profundamente, ao longo das décadas de 20 a 70 do século XIX, o desenvolvimento de um gênero literário que, nas últimas três décadas daquele século, se constituiu o modelo formal preferido de apresentação dos dados etnográficos dos Völkerkundler, de Bastian a Koch-Grünberg e além.

Estamos, é claro, falando dos relatos de viagem. Trata-se de um gênero literário antigo (cf. Campbell, 1988), que somente ao longo da primeira onda de expansão colonialista do Ocidente (do século XV ao XVII) começou a se diferenciar claramente, apresentando-se na forma de diário (relato pessoal de uma experiência individual, quase sempre descrita na primeira pessoa do singular) e na de crônica (escrita na terceira pessoa, freqüentemente por um compilador) como subvariedades claramente diferenciadas do gênero (Bitterly, 1976, p. 24-34).

No século XVIII, finalmente, isto é, ao longo da segunda onda de expansão colonial, une-se a essas duas uma outra forma, fruto direto do 
Revista de Antropologia, São Paulo, USP, 2005, v. 48 No 2.

crescente interesse de diversas ciências e cientistas por fatos plenamente ausentes nas obras anteriores do gênero ${ }^{13}$. Surgem, de tal maneira, os relatos científicos de viagens (de Condamine a Darwin), obras escritas por cientistas, embora não exclusivamente para cientistas, mas que se dirigiam à totalidade daqueles que, pelo estudo de alguma ciência, eram capazes de entender a realidade por meio da nova perspectiva epistêmica descoberta por Descartes, Newton, Laplace. A leitura científica da realidade de continentes longínquos, oferecidas por esse novo tipo de relato de viagem, não acabou com os contrastes surpreendentes (hoje diríamos exóticos) entre o "aqui" (Europa, Inglaterra, Alemanha etc.) e o "lá", que constituíam o enfoque central dos relatos anteriores. No entanto, os viajantes-cientistas esforçavam-se para tornar esses contrastes entendiveis, como as muitas variedades necessárias de um real único e sistemático em todas as partes e em todos os tempos.

Ora, a "Voyage" de Alexander von Humbold apresenta, sem dúvida, o mesmo paradigma dos relatos desse tipo. Dirigia-se de maneira explícita ao leitor erudito (na Alemanha da época, o Bildungsbürger) que, pela mesma forma de descrição, era levado a perceber claramente até os detalhes mais surpreendentes da realidade de partes da América descritas por esse autor como momentos necessários de um mundo único, determinado em todos os lugares e aspectos pelas mesmas leis, tendências ou, minimamente, regularidades, na vigência de condicionamentos acidentais (astronômicos, físicos, biogeográficos etc., isto é, históricos) particulares a cada local. Não surpreende a um homem instruído nas ciências naturais da época que a redução científica do exótico à regularidade de um mundo sistemático em todas as partes centrava-se no aspecto físico do mundo. Mas aquela nova visão da realidade mundial que a obra de Humboldt revela e propóe - esse novo "jeito" científico de analisar a diversidade empírica do real - prontamente foi aplicada também 
(até mesmo pelo próprio Humboldt) àquele tipo de fato que hoje em dia chamamos de social ou cultural.

Só que, neste ponto, a oposição epistemológica (que encontramos já em Wilhelm von Humboldt) entre o reducionismo positivista do Iluminismo e das "ciências naturais" mais avançadas na época e o holismo (culturalismo-coletivismo) romântico, em particular dos herderianos, resultou em teorias alternativas que (meio século depois, justamente naquele momento em que uma fração destes últimos logrou finalmente transformar a sua interpretação sociopsicológica de Herder numa nova disciplina acadêmica, chamada Völkerkunde) alguns filósofos alemães (os neokantianos Rickert, Windelband e Dilthey) declararam "(epistemo)logicamente incomensuráveis” entre si. Tratava-se, sem dúvida, de uma tentativa (desesperada, aliás) de salvar as próprias convicções holísticas em face de recentes triunfos do positivismo (reducionismo) na demografia e biologia (pós-darwiana), por exemplo.

Ora, nos tempos de Wilhelm e Alexander von Humboldt, o culturalismo romântico ainda parecia meramente outra interpretação dos fatos sociais - interpretação alternativa àquela dos defensores mais radicais tanto do materialismo como também do idealismo historicista. Como já vimos, essa alternativa relacionava a diversidade dos fatos sociais (em todos os tempos e em todos os lugares) a condições locais (geográficas) e temporais (históricas), embora sempre intermediadas por uma psicologia coletiva (W.v. Humboldts Volkscharaktere) que, historicamente, é - ela mesma - produto da história do enfrentamento diferenciador do "Geist" humano (W.V.Humboldts Gattungsckarakter) com os condicionamentos locais e temporais passados, criando e mantendo coletividades psicossocialmente (hoje, diríamos culturalmente) diferenciadas. 
Revista de Antropologia, São Paulo, USP, 2005, v. 48 № 2.

\section{Bildung, Kultur e Charakter}

Bildung (educação) e Kultur (cultura) são conceitos quase idênticos no pensamento alemão, pelo menos desde o Romantismo até a primeira metade do século passado.

Como já indicamos, particularmente para o Bildungsbürgertum, a boa educação foi - e segue sendo - aquilo que dá cultura às pessoas, o que torna as pessoas "cultas". Por outro lado, os integrantes do Bildungsbürgertum entenderam a cultura como precondição imprescindivel à mesma possibilidade de o homem educar (outros) bem. Destarte, a cultura e a educação pareceram meramente duas faces de uma mesma moeda: do Charakter e/ou da personalidade social (coletiva) das pessoas; isto é, de seu Volkscharakter; e também geradora e expressão de uma moralidade cívica (coletiva) particular, ética e estética própria a qualquer povo. Tal ethos (Max Weber) fundamentava uma "visão (interpretação) do mundo" e um estilo de vida coletivo inconfundível que, supostamente, marcava todas as açôes dos integrantes de tais coletividades e, por meio dessas, a estrutura e a superestrutura social (a organização social e as crenças, as imaginações e a produção artística), assim como todos os produtos materiais que essas ações geram.

Como vimos, essa interpretação da cultura-educação como uma força moldadora e unificadora por trás das ações, das idéias e dos valores dos integrantes de qualquer povo e, por meio destes, também dos seus "produtos" (materiais e imateriais) opóe-se frontalmente à tentativa dos iluministas e positivistas da época de identificar uma ética e uma estética, um único estilo de vida humano universal como objetivamente (e exclusivamente) racional (civilização). Na realidade, foi contra o absolutismo dessa "razão" que a teoria social alemã argumentou, desde Herder, a respeito da existência de um Geist ou Charakter nacional (ou dos po- 
Erwin H. Frank. Viajar é preciso...

vos) que - nos cem anos posteriores - chegaram a ser identificados com o termo "cultura".

Ora, é essa a idéia-chave de toda uma linha de argumentação que, em conseqüência e com constante referência à obra dos irmãos Humboldt (sobretudo a "cosmografia" de Alexander), desde os anos 40 do século XIX, discutia na Alemanha a importância relativa da geografia (realidade material) versus a psicologia (a autonomia do Geist), ou também da difusão de invenções versus a dinâmica criativa própria da cultura (historicamente constituída). Afinal, foi essa linha de discussão que nos anos 1850-1870 provocou, entre outros, a ruptura teórica e institucional dos geógrafos alemães (na linha de Ritter e Ratzel) da Völkerkunde (culturalista) de um Waitz e sobretudo de Bastian, por meio da aproximação crítica deste último com a psicologia neokantiana. Em realidade, a Völkerkunde (etnologia) de Bastian foi, em essência, uma antropo-psicologia, historicista, holística e decididamente antiindividualista, isto é, social. No centro dessa Völkerkunde, está um modelo (antideterminista) da dinâmica de constituição (e de mudanças históricas) das culturas (povos) humanas, com a particularidade da subordinação $a$ priori da geografia - fator determinante na variedade ratzeliana do mesmo modelo - à força criativa própria de cada cultura.

$\mathrm{Na}$ visão antropológica de Bastian, as culturas humanas são essencialmente distintas. Se mesmo assim há semelhanças entre elas, isso se explica, por um lado, pelo fato de que todas elas têm de resolver certos problemas (ambientais) comuns, por outro (e principalmente), porque há certas "idéias elementares" que, segundo o famoso ditado do mestre, se repetem "com férrea necessidade" em todas elas (Köpping, 1983). Ora, se o ambiente dos povos provoca, às vezes, desenvolvimentos convergentes entre eles, a principal causa das semelhanças culturais não é, para Bastian, a natureza externa, mas a natureza interna das culturas - justa- 
mente as idéias elementares, provas inquestionáveis da "unicidade psíquica" da humanidade.

Mas como estudar idéias universais? Sobretudo, como estudá-las, se elas, segundo o próprio Bastian, nunca se expressam diretamente, senão na forma indireta dos Völkergedanken (idéias de povos concretos), que são especificações históricas e "situacionistas" de cada um deles, intermediadas pelo Volksgeist (espírito dos povos) ou pela Volkseele (alma dos povos), adaptados às exigências do ambiente histórico e da própria constituição física dos povos?

\section{Koch-Grünberg como Völkerkundler}

Com essa pergunta estamos de volta a Koch-Grünberg, cuja praxe de pesquisa e documentação etnográfica visou justamente tornar acessível à Völkerkunde o máximo de dados imprescindíveis à identificação das idéias universais por trás de suas formas particularizadas de Völkergedanken (Mühlmann, 1948).

Três premissas orientaram Koch-Grünberg nesse esforço. Conforme a primeira delas, a cultura, força geradora detrás dos Völkergedanken, precisa dos efeitos gerados por ela e só pode ser estudada por meio deles, ou seja, por meio de uma antropologia comparativa das ações, das idéias e das produções sociais. Só que, como ela realmente se expressa em qualquer ato, fato e produto sociocultural, a etnografia dos Völkerkundler (e de Koch-Grünberg) carecia necessariamente de um foco, condenando o etnógrafo à documentação detalhada de um máximo de idéias, ações e produtos de açôes sociais (idéias ${ }^{14}$, estruturas sociais, instituições e objetos da cultura material freqüentemente denominados "formas" culturais) observáveis em algum povo - um campo de dados tão vasto que os Völkerkundler em geral sabiam afinal organizá-lo so- 
mente pela casualidade do calendário de suas viagens e pelas exigências específicas do próprio genre literário (relatos de viagem), escolhido e preferido para a apresentação de seus resultados ${ }^{15}$. Isto é, sem dúvida, a razão última dos etnógrafos, dentre os Völkerkundler alemães, para optarem firmemente pela forma literária do relato de viagem (científico), mesmo sabendo - e assim o expressando de vez em quando - que essa forma e o estilo itinerante de levantamento de dados etnográficos a ela adequado impediam um conhecimento mais profundo da totalidade e da dinâmica internas (sistematicidade) de cada cultura.

A segunda premissa da etnografia de Koch-Grünberg fundamentase naquele capítulo da teoria de Bastian que atribuiu parte das variações concretas no espaço das expressóes concretas que a mesma idéia (elementar) pode apresentar em dois ou mais povos às diferenças ambientais versus a diferença na constituição (psico)física (raça) dos integrantes de duas ou mais culturas. Longe de entender tais variaçôes como momento complicador do projeto, os Völkerkundler as consideravam uma vantagem, facilitando o passo analítico regressivo da superfície das expressões culturais à sua causa implícita: a própria cultura. Só que, para se poder aproveitar essa vantagem, parecia ser indispensável observar e documentar detalhadamente um máximo de variações étnicas em um maior número possível de grupos culturais distintos, embora fossem da mesma região, para evitar o "erro" principal do evolucionismo: a generalização descontrolada.

Isso nos refere, finalmente, à terceira e última premissa da etnografia da Völkerkunde em geral, e especificamente à etnografia de Koch-Grünberg, fundamentada na premissa bastiana de que a dinâmica de qualquer cultura é sempre genuinamente histórica ${ }^{16}$. Portanto, somente a historiografia das culturas é mesmo capaz de revelar os segredos de seu desenvolvimento. Ora, para todos os Völkerkundler, o modelo (ou ideal) 
Revista de Antropologia, São Paulo, USP, 2005, v. 48 no 2.

de uma "verdadeira" historiografia cultural era claramente a lingüística comparativa, capaz de revelar e de organizar relações entre os povos, além das semelhanças e das distinções entre eles. Daí o interesse agudo e constante dos etnólogos, inclusive Koch-Grünberg, por listas de palavras, mas também textos (mitos, canções, provérbios), como matéria-prima para a classificação, a delimitação e a análise das relações internas entre os povos visitados ${ }^{17}$. Mais ainda, como já vimos, as falas (qualquer fala) dos nativos, transcritas textualmente, sobretudo provérbios, rimas, poemas, mitos, contos, eram, em outro sentido, de singular importância para a Völkerkunde, pois eram vistos pelos filósofos idealistas alemães como a expressão mais "pura" (direta) da própria visão de mundo e até da lógica de raciocínio particular de qualquer povo (cultura $)^{18}$.

Eis aí os elementos principais que orientaram a praxe de KochGrünberg como etnógrafo (e dos demais entre os Völkerkundler) e também a forma predileta da apresentação de seus resultados.

Fosse por onde fosse que eles andassem, sempre se esforçaram em observar (e em documentar minuciosamente) o maior número possivel de idéias, ações e produtos de ações (instituições, tradições orais e objetos) dos integrantes dos povos visitados, com particular ênfase no meio ambiente, na cultura material, na língua e na mitologia ${ }^{19}$ desses povos. Levando ainda em conta o inegável talento de Koch-Grünberg de transformar as suas viagens em divertidíssimos textos (vide 2005, ou os volumes I e III de Vom Roroima zum Orinoco) e o seu conhecido pioneirismo metodológico (uso sistemático da câmera fotográfica, da filmadora, do fonógrafo etc.), não resta dúvida nenhuma de que ele representava mesmo, desde o início de sua carreira, o ideal de um etnógrafo para a Völkerkunde de sua época - uma real personificação de seu programa de pesquisa básico -, o que explica finalmente a surpreendente carreira que o transformou em um dos principais representantes desse programa. 
Erwin H. Frank. Viajar é preciso...

\section{Um projeto humanamente impossível}

Só que, no mesmo momento em que Koch-Grünberg logrou convencer seus pares e superiores de ser mesmo um executor ideal de seu projeto etnográfico (tanto que em recompensa o receberam de braços abertos no próprio grupo e o honraram com títulos e postos), esse mesmo projeto já tinha entrado em crise - uma crise que, curiosamente, o próprio êxito de Koch-Grünberg contribuiu, e muito, para tornar ainda mais aguda.

De fato, nada melhor que a obra de Koch-Grünberg para mostrar que o projeto etnográfico da Völkerkunde era mesmo difícil, até mesmo humanamente impossivel de se realizar. Pois, como vimos, para entender (verstehen) qualquer cultura ou povo, esse projeto declarou imprescindivel conhecer (estudar-experimentar-documentar) o máximo de suas "realizaçôes" na forma de idéias (falas, textos), ações e produtos de ações (instituições e objetos) concretos. Não havia idéia, ação ou objeto material privilegiado, isto é, mais ou menos importante que qualquer outro. Afinal, tudo era da mesma maneira "culturalmente constituído" e, como tal, igualmente importante ou interessante para a Völkerkunde como ponto de partida para a aproximação hermenêutica de sua fonte ou causa. Mais ainda: como o projeto científico da Völkerkunde era mesmo antropologia - uma ciência essencialmente comparativa - ou nada, no mesmo momento de se negar a delimitar o âmbito de idéias, ações e objetos de interesse particular em qualquer povo, ela ainda obrigava o etnógrafo a viajar incansavelmente em regiões etnográficas extensas, sob pena de desqualificar os resultados obtidos em um povo da região pela impossibilidade de tratá-lo comparativamente. Ou seja, o projeto científico geral da Völkerkunde negou a seus etnógrafos o tempo indispensável para aprofundar a pesquisa em qualquer grupo específico, obrigando-os a uma eterna peregrinação de grupo em grupo, num vão intento de ana- 
Revista de Antropologia, São Paulo, USP, 2005, v. 48 № 2.

lisar e documentar a estruturação étnico-regional como base para a reconstrução historiográfica da constituição da cultura atual de qualquer um desses povos.

Ora, Theodor Koch-Grünberg é, com muita razão, famoso pelo enorme esforço que desenvolveu, em todas as suas viagens ao Brasil, no sentido de cumprir ao mesmo tempo com ambas as exigências (contraditórias) acima indicadas. Em primeiro lugar, para facilitar a requerida documentação ampla do cotidiano das culturas indígenas, ele experimentou constante e sistematicamente novas técnicas etnográficas como a fotografia, a filmagem e as gravações (de canções e mitos), mesmo sendo difícil manusear "gramofone", além de esboçar figuras e situações com tinta e lápis em seu diário e estimular os índios a realizarem os próprios desenhos também.

Em segundo lugar, de qualquer índio que encontrava em seu caminho e/ou que alguém lhe indicava como membro de uma tribo distante, ele solicitava minimamente uma lista de palavras em sua língua materna, além de informações pormenorizadas sobre a localização exata, o número e o modo de vida de seu grupo. De tal maneira, Koch-Grünberg logrou acumular quantidades deveras impressionantes de dados etnográficos, em geral de excelente qualidade e em um tempo mínimo. Por exemplo, em menos de três meses que permaneceu efetivamente nos lavrados de Roraima, Koch-Grünberg coletou uma imensidade de dados - para não falar dos vários milhares de objetos que ali colecionou que precisaram, afinal, de cinco pesados volumes para serem apresentados de forma concisa. Mas esses cinco volumes ilustram também a seriedade dos problemas que lhe foram causados por sua adesão acrítica ao projeto científico da Völkerkunde e a sua procura desesperada de novas soluções para eles.

Para especificar: cada um dos cinco volumes pertence a um diferente gênero literário-científico. $\mathrm{O}$ primeiro é um diário de viagem, no senti- 
do clássico do termo. O segundo apresenta uma ampla coleção de contos e mitos dos Taulipang, dos Macuxi e dos Wapishana. O terceiro, finalmente, é o que se aproxima mais de uma etnografia dos Taulipang, no sentido pós-malinowskiano, hoje clássico, além de apresentar uma análise musicológica de cançôes do mesmo povo. O quarto volume é uma contribuição à lingüística comparativa de três dúzias de línguas indígenas distintas, faladas entre os rios Branco e Orenoco. E há ainda um quinto volume que o próprio Koch-Grünberg chamou de Atlas de tipos indigenas - a contribuição (fotográfica) deste autor à antropologia física de sua época. A totalidade dessa obra representa claramente um esforço (já algo desesperado, diria eu) de satisfazer todos os aspectos contraditórios do projeto etnográfico da Volkerkunde numa única elaboração e com igual intensidade e profundidade.

Mas nem todos os Völkerkundler tinham, é claro, o talento, a energia e a paciência de um Theodor Koch-Grünberg. Ele mesmo lamentava que, afinal, não obstante o peso de seu trabalho, em vista do que restava ainda para registrar, a sua obra-prima não passava de um fragmento. Tentamos mostrar neste ensaio que, muito mais do que um fragmento, toda a obra de Koch-Grünberg constitui-se em um eterno monumento a um projeto científico ambicioso demais e, por isso mesmo, desde o momento de sua criação, condenado ao fracasso.

\section{Notas}

1 Hermann Meyer (1871-1932) estudou geografia em Heidelberg, Strassburgo e Berlim, onde trabalhou no Königliches Museum für Völkerkunde. Em 1885, recebeu título de doutor da Universidade de Jena, apresentando uma tese sobre Arcos e flechas do Brasil Central. Em 1895-1897, realizou uma primeira expedição ao interior do Brasil, chegando até o alto rio Xingu. Um ano depois, voltou ao 
Brasil (desta vez acompanhado por Koch-Grünberg) e, novamente, tentou chegar ao Xingu. A expedição naufragou no alto rio Ronuro, perdendo quase a totalidade de seu equipamento, mesmo antes de alcançar a primeira aldeia indígena. Somente com grandes dificuldades, Meyer e os seus companheiros conseguiram voltar a Curitiba. Essa experiência levou Meyer a abandonar a Völkerkunde. Ele passou os últimos anos de sua vida no sudoeste do Brasil, organizando (e financiando) colônias de imigrantes alemães (Hermannstädter, 2004). Foi recentemente publicado na Alemanha o "diário" de Koch-Grünberg da segunda expedição de Meyer (KochGrünberg, 2004).

2 Neste ensaio, chamaremos Völkerkunde não aquela ciência oferecida em algumas universidades alemãs do final do século XIX, mas sim o projeto cientifico adotado e defendido pelos fundadores e representantes (acadêmicos ou não) daquela ciência ao longo de mais de meio século (1870-1930). Curiosamente, uma variedade tardia (e geograficamente efêmera) desse projeto sobreviveu à rápida decadência da Völkerkunde na própria Alemanha após a Primeira Guerra Mundial e persiste, ainda hoje, nos Estados Unidos, na forma das diversas versões do culturalismo, fundamentada nos ensinamentos de outro etnógrafo-viajante, aluno e colaborador de Adolf Bastian e Karl von den Steinen no Museu de Berlim: o "pai" da antropologia norte-americana, Franz Boas.

3 Em 1902, o museu contratou Koch-Grünberg como ajudante científico (Wissenschaftlicher Hilfsarbeiter), posição que lhe garantiu um salário paupérrimo e que ocupou até 1909.

4 Inicialmente, estava prevista que a expedição percorreria o rio Purus e o rio Ucayali (no Peru), regiōes de interesse particular para o superior imediato de KochGrünberg no museu, Karl von den Steinen. Em Manaus, Koch-Grünberg decidiu não somente redirecioná-la, mas também estendê-la de um ano para dois, provocando duras críticas de seu mentor.

5 Recentemente, uma primeira tradução da obra para o português foi lançada pela Editora da Universidade Federal do Amazonas (cf. Koch-Grünberg, 2005). Existe uma tradução para o espanhol, publicada há décadas em Bogotá, Colômbia.

6 Até hoje, a livre-docência, em geral, é outorgada em reconhecimento a uma contribuição destacada à ciência. Na Alemanha, ela é precondição para concorrer a vagas universitárias de professor. 
$7 \mathrm{Na}$ Alemanha, a livre-docência outorga o direito de ensinar numa universidade; mas direito que se perde se o livre-docente não oferecer disciplinas, mesmo que a universidade não tenha recursos para lhe pagar o serviço.

8 O apelido "mandarins" foi inicialmente (século XIX) aplicado aos chefōes de diversos ramos da ciência (sobretudo das ciências naturais) da Universidade de Berlim (Humboldt Universität). Posteriormente, seu uso estendeu-se a qualquer "Ordenarius" com influência sobre a política de contratação em sua universidade.

9 As bibliografias de Koch-Grünberg contêm poucos itens explicitamente teóricos. Até seus trabalhos comparativos são, em grande parte, exposiçôes dos próprios dados etnográficos. Mas é preciso enfatizar neste contexto (como tentaremos aqui mostrar) que a própria etnografia de Koch-Grünberg como tal constituiu um projeto genuinamente teórico.

10 Neste ensaio, usamos o conceito de "projeto científico" no sentido de projeção programática de um "fazer" científico específico, determinado pelo lugar imaginado da ciência projetada no espectro vigente das disciplinas acadêmicas estabelecidas.

11 Trata-se, sem dúvida, de uma variedade do historismo culturalista de Herder. Porém, o importante aqui não é a idéia "em si", mas o esforço de teorização de uma hermenêutica para esse historismo herderiano.

12 Toda a obra de Alexander von Humboldt (vide sobretudo 1808-1834, 1808 e 1845-1862) expressa a mesma rejeição (Zammito, 2002) da idéia de uma incomensurabilidade epistemológica entre o empirismo e a metafísica, rejeição esta que se manifesta claramente em sua vontade holística de entender (em alemão: verstehen) a realidade "como um todo", inclusive as manifestações (idéias-ações) humanas (Köchy, 2002; Ette, 2000; Siegel, 2003).

13 A explicação da ausência desses dados nos relatos de viagem anteriores ao século XVIII explica-se, é claro, pelo fato de que foi somente na segunda metade daquele século, e em tempos posteriores (Linné, Lyell, Darwin), que avanços teóricos (na biologia e na geologia, por exemplo) os tornaram relevantes.

14 Aqui, no sentido de "pensamentos" expressos diretamente ou indiretamente via provérbios, poesias, canções etc.

15 As milhares de páginas de anotações, nunca publicadas, que Franz Boas acumulou ao longo de 50 anos de pesquisa sobre os Kwakiutl constituem outro exemplo claro de uma etnografia na tradição da Völkerkunde. Só que a etnografia de Boas 
careceu inclusive da organização formal de seus dados, que Koch-Grünberg ainda encontrou na forma literária dos relatos de viagem.

16 Isto é, histórico não no sentido da historiografia especulativa dos evolucionistas, mas no sentido concreto do "historicismo".

17 Nesse sentido, não foi nada casual que Hermann Meyer tivesse convidado justamente o jovem filólogo Theodor Koch a participar de sua segunda viagem ao Brasil.

18 Com relação ao papel da poesia (e do poeta) como expressão superior do espírito nacional nas teorias dos sociólogos (não somente alemães) da segunda metade do século XIX, cf. Lepenies (1996).

19 É bem verdade que a praxe etnográfica de Koch-Grünberg (e dos demais Völkerkundler alemães - compare-se de novo com Franz Boas) foi também fortemente determinada por seu papel de empregado-colecionador de museus etnográficos e pelo fato de que muitas e artisticamente espetaculares peças etnográficas tinham de financiar pelo menos parte dos enormes custos (daquela época) de suas expediçōes. Só que, do ponto de vista do projeto científico ao qual se dedicou (e outros se dedicaram), não existiu incomensurabilidade nenhuma entre o papel de colecionador da cultura material e aquele de documentador (e analista) da cultura dos povos em geral. Ao contrário, além de constituir expressão direta dos Völkergedanken tão (i)mediata como qualquer costume ou fala, a cultura material (transformada em acervo museológico) ainda oferecia a possibilidade de (re)experimentar diretamente (e estudar) os Völkergedanken de povos longínquos anos após o trabalho de campo, até mesmo para interessados que nunca saíram da Europa. Cabe lembrar nesse contexto que Karl von den Steinen, após sua Habilitation em Marburg, negou-se a ensinar Völkerkunde naquela cidade por falta de um museu etnográfico, sem o qual, segundo declarou em carta àquela instituição, era simplesmente impossível ensinar Völkerkunde (Kraus, 2001). 


\section{Bibliografia}

ADAMS, P. G.

1962 Travelers and travel liars, 1660-1800, New York, Dover Publications.

BITTERLI, U.

1876 Die 'Wilden' und die 'Zivilisierten', München, Beck.

BUNZL, M.

1996

"Franz Boas and the humboldtian tradition: from Volksgeist and Nationalcharakter to an anthropological concept of culture", in STOCKING, G. W. JR. (ed.), Volksgeist as Method and Ethic, Madison, Univ. Wisconsin Press, p. $17-78$.

CAMPBELL, M. B.

1988 The witness and the other world; exotic european travel writing, 400-1600, Ithaca, Cornell University Press.

ETTE, O.

2000

“Unterwegs zum Weltbewusstsein”, HiN, vol. I(1). Disponível em <www.unipotsdam.de/u/romanistik/humboldt/hin>. Acesso em 20/1/2005.

FABER, G.

1956

"Theodor Koch-Grünberg, Der Ethnologe Nordwest-Brasiliens", Tribus, NS, Bd.4/5, 1954-55, Stuttgart, p. 256-64.

FRANK, E.

2002

“Os irmãos Schomburgk como fontes da etnohistória de Roraima”, trabalho apresentado em Reunião da ABA.

GIESEN B.

1993

Die Intellektuellen und die Nation, Frankfurt, Suhrkamp.

GISEN, B. \& JUNGE, K.

1991

"Vom Patriotismus zum Nationalismus: Zur Evolution der 'Deutschen Kulturnation'”, in GIESEN, B. (ed.), Nationale und Kulturelle Identität, Frankfurt, Suhrkamp, p. 255-303. 
Revista de Antropologia, São Paulo, USP, 2005, v. 48 № 2.

HABERMAS, J.

1962 Strukturwandel der Öffentlichkeit, Untersuchungen zu einer Kategorie der Bürgerlichen Gesellschaft, Neuwied.

HARRIS, M.

1968 The rise of anthropological theory, New York, Crowell.

HERMANNSTÄDTER, A.

2004 "Hermann Meyer: Der Sertão als schwieriger sozialer Geltungsraum", in KOCH-GRÜNBERG, T. Die Xingu-Expedition (1898-1900): Ein Forschungstagebuch, Michael Kraus (Ed.), Köln/Weimar, Böhlau, p. 60-64.

HARTMANN, G.

1980 "Theodor Koch-Grünberg", Boletín de la Asociación Cultural Humboldt, Anos 1978-79, Bd.15-16, Caracas, p. 9-18.

HERDER, J. G.

1995 Também uma filosofia da história para a formação da humanidade, Lisboa, Antígona.

HUMBOLDT, A. VON \& BONPLAND, A.

1808-1834 Voyage aux régions équinoxiales du nouveau continent, fait in 1799, 1800, 1801, 1802, 1803, et 1804, Paris.

KOCH-GRÜNBERG, Th.

1890

$1909-1910$

$1916-1928$

2004

2005
"Animismus der südamerikanischen Indianer [Sobre o animismo dos índios sulamericanos]", Internationales Archiv für Ethnographie, 1900, Beilage zum Bd. 13. Zwei Jahre unter den Indianern, Reisen in Nordwest-Brasilien, 2 vols., Berlim.

Vom Roroima zum Orinoco, Berlim, Dietrich Reimer, vol. 2 e 1; e Stuttgart, Strecker u. Schröder, vol. 3 a 5.

Die Xingu-Expedition (1898-1900): Ein Forschungstagebuch, Kraus, M. (ed.), Köln/Weimar, Böhlau, 2004, p. 60-64.

Dois anos entre os indígenas. Viagens no noroeste do Brasil (1903-1905), Manaus, Edua. 
Erwin H. Frank. Viajar É preciso...

KÖCHY, K.

2002

"Das Ganze der Natur, Alexander von Humboldt und das romantische Forschungsprogramm", HiN, Vol. III(5). Disponível em <www.unipotsdam.de/u/romanistik/Humboldt/hin/hin5>. Acesso em 1/9/2004.

KOCKA, J.

1987

Bürger und Bürgerlichkeit im 19, Jahrhundert, Göttingen.

KÖPPING, K.-P.

1983 Adolf Bastian and the Psychic Unity of Mankind, Londres, Queensland Press.

KRAUS, M.

2001 "..ohne Museum geht es nicht”, in VOELL, S. (ed.). Die Völkerkundliche Sammlung de Phillips-Universität Marburg, Marburg, Curupira, p. 31-66.

KUTSCHER, G.

1976 "Berlin como Centro de Estudos Americanistas", Indiana, Beiheft 7, Berlim.

LAZARUS, M. \& STEINTAL, H.

1859 "Einleitende Gedanken über Völkerpsychologie", Zeitschrift für Völkerpsychologie und Sprachwissenschaft, vol. 1, p. 1-73.

LEPENIES, W.

1996 As três culturas, São Paulo, Edusp.

MÜHLMANN, W.E.

$1948 \quad$ Geschichte der Anthropologie, Frankfurt.

RATZEL, F.

$1891 \quad$ Antropogeographie, 2 vols., Stuttgart.

RICE, $\mathrm{H}$.

1928 "The Rio Branco, Uraricuera, and Parima: surveyed by the expedition to the Brazilian Guyana from August 1924 to June 1925”, Geographical Journal, vol. 71, p. $113-43$, p. $209-23$, p. $345-57$.

1978 Exploração na Guiana Brasileira, São Paulo, USP. 
Revista de Antropologia, São Paulo, USP, 2005, v. 48 № 2.

RITTER, K.

1852

Abhandlungen zur Begründung einer mehr Wissenschaftlichen Behandlung der Erdkunde, Berlim, 1852.

SAHLINS, M. D.

2004

Esperando Foucault, ainda, São Paulo, Cosac \& Naify.

SCHADEN, E.

"Pioneiros alemães da exploração etnológica do Alto Xingu, in PENTEADO COELHO, V. (org.). Karl von den Steinen: um século de antropologia no Xingu, São Paulo, USP, p. 111-29.

SIEGEL, E-M.

2003

"Prepräsentation und Augenschein", HiN (Humboldt im Netz), vol. IV(7). Disponível em <www.uni-potsdam.de/u/romanistik/humboldt/hin/hin7>. Acesso em $1 / 9 / 2004$.

STOCKING JR., G. W.

1984

Functionalism Historized: essays on British Social Anthropology, Madison, Univ. of Wisconsin, History of Anthropology, vol. 2.

1987 Victorian anthropology, New York, Free Press.

TURZA, J. e O.

"Die Sammlung von Theodor Koch-Grünberg im Freiburger Museum für Völkerkunde", Veröffentlichungen des Museums für Völkerkunde, Bd. 4, Freiburg, p. 35-64.

VOELL, St. (Ed.)

2001

".ohne Mueseum geht es nicht" - Die Völkerkundliche Sammlung der PhilippsUniversität Marburg, Marburg, Curupira.

ZAMMITYO, J. H.

2002

Kant, Herder: the birth of anthropology, Chicago, University of Chicago Press.

ZERRIES, O.

1972

"In memoriam Theodor Koch-Grünberg", Tribus, 21, Stuttgart, p. 7-10. 


\begin{abstract}
Taking the ethnography of Theodor Koch-Grünberg as ideal realization of the scientific project of Völkerkunde (German anthropology), ever since its invention by Waitz and, principally Adolf Bastian, up to its self-elimination in the "Third Reich", we analyze initially the roots of this project in German philosophy since Herder, up to the neo-Kantian rupture between the natural and the social (or cultural) sciences, in midst $19^{\text {th }}$ century. After that, we try to show that, as a program for ethnography, the epistemic presuppositions of Völkerkunde were, ever since its beginnings, condemned to fail, - even considering the heroic trails of Koch-Grünberg.

KEY-WORDS: history of anthropology, Völkerkunde, Theodor KochGrünberg, ethnography.
\end{abstract}

Aceito em novembro de 2005. 